\title{
Controlled Assembly of AIE Active Bolaamphiphilic Mac- romolecules into Luminescent Organic Nanoparticles Op- timized for Two-Photon Microscopy in vivo
}

\author{
Jean Rouillon, ${ }^{\text {a }}$ Lamiaa M.A. Ali, ${ }^{\text {bc }}$ Kamel Hadj-Kaddour, ${ }^{b}$ Raphaël Marie-Luce, ${ }^{\text {a }}$ Mélanie Onofre, ${ }^{b}$ \\ Sandrine Denis-Quanquin, ${ }^{a}$ Marion Jean, ${ }^{d}$ Muriel Albalat, ${ }^{d}$ Nicolas Vanthuyne, ${ }^{d}$ Guillaume Micouin, ${ }^{\mathrm{a}}$ \\ Akos Banyasz, a Magali Gary-Bobo, ${ }^{\text {bb }}$ Cyrille Monnereau*a and Chantal Andraud ${ }^{*}$ \\ a Univ. Lyon, ENS Lyon, CNRS, Laboratoire de Chimie, UMR 5182, 46 Allée d'Italie, 69364 Lyon, France. E- \\ mail: cyrille.monnereau@ens-lyon.fr \\ b IBMM, Univ Montpellier, CNRS, ENSCM, Montpellier, France. E-mail: magali.gary-bobo@inserm.fr \\ c Department of Biochemistry Medical Research Institute, University of Alexandria, 21561 Alexandria, Egypt. \\ d Aix Marseille University, CNRS, Centrale Marseille, iSm2, Marseille, France
}

\begin{abstract}
The (Z) and (E) isomers of an extended tetraphenylethylene-based chromophore with optimized two-photon induced luminescence properties are separated and functionalized with water-solubilizing pendant polymer groups, promoting their self-assembly in physiological media in the form of small, colloidal stable organic nanoparticles. The two resulting fluorescent suspensions are then evaluated as potential two-photon luminescent contrast agents for intravital epifluorescence and two-photon fluorescence microscopy. Comparisons with previously reported works involving similar fluorophores devoid of polymer side chains illustrate the benefits of the later functionalization regarding the control of the self-assembly of the nanoobjects, and ultimately their biocompatibility towards the imaged organism.
\end{abstract}

\section{INTRODUCTION}

Since its invention in the late 1990's two-photon fluorescence microscopy has experienced impressive developments, ${ }^{1-2}$ and has opened unprecedented perspectives in tissues imaging that have substantially benefited such diverse fields as neurobiology, ${ }^{3}$ physiology, ${ }^{4}$ embryology ${ }^{5}$ and tissue engineering. ${ }^{6}$ These developments have been achieved thanks to combined advances in the optical setups design and in the developments of increasingly sophisticated and selective endogenous (green fluorescent proteins) ${ }^{7}$ and exogenous (synthetic organic chromophores and nanoparticles) fluorescent contrast agents. ${ }^{8-11}$

In this framework, the conception of molecular probes or nanoobjects that combine sizeable two-photon induced emission properties with good solubility (or colloidal stability) in physiological media has been a major issue, on which we have been extensively working in recent years. ${ }^{12-14}$

In previous reports, we have proposed chromophore functionalization with water solubilizing poly(hydroxyethylacrylate) (PHEA) polymeric side chains as a relevant approach to achieve high biocompatibility of molecular bioprobes. ${ }^{15}$ We have shown that this functionalization could efficiently shield the molecule from interactions with its local environment, ensuring solubility of inherently lipophilic and prone-to-stacking fluorophores into aqueous media, and keeping luminescence efficiencies high. This strategy has been used in the making of fluoro- phores that have already found promising application for diverse bio-related applications such as intravital imaging of cerebral vascularization ${ }^{16-18}$ or the detection of biomolecules (dsDNA,${ }^{19}$ G-quadruplexes ${ }^{20-21}$ and proteins ${ }^{22}$ ) in complex physiological media.

In parallel, we have recently reported on extended tetraphenylethylene (TPE) derivatives - a class of molecules classically used for their Aggregation-Induced Emission (AIE) properties $^{23-25}$ in particular for bioimaging and biosensing applications $^{26-31}$ - that had been specifically designed to maximize the two-photon emission properties of their aggregates. ${ }^{32}$ In the course of this study, it turned out that, in spite of the excellent colloidal stability and excellent spectroscopic properties of the suspension obtained by nano-precipitation of $\mathbf{T} \mathbf{T}^{\mathbf{O M e}}$, only limited control over the assembly was achieved : as a result, mixtures of large $(\mathrm{d}>100 \mathrm{~nm})$ and disperse nanoparticles were obtained with detrimental outcome on the long-term survival of the imaged zebrafish.

It has already been established in previous literature reports that the self-assembly of fluorophores containing macromolecules (either in the form of grafted polymers or conjugated polymers) usually led to smaller and better controlled self-assembly compared to dye-loaded nano-objects obtained by conventional nano-precipitation methods. ${ }^{33}$ In particular, direct self-assembly of fluorescent amphiphilic polymers upon dispersion in aqueous media has proved to be a remarkably effective approach for the synthesis of small $(10-14 \mathrm{~nm})$ monodisperse nanoparticles, 


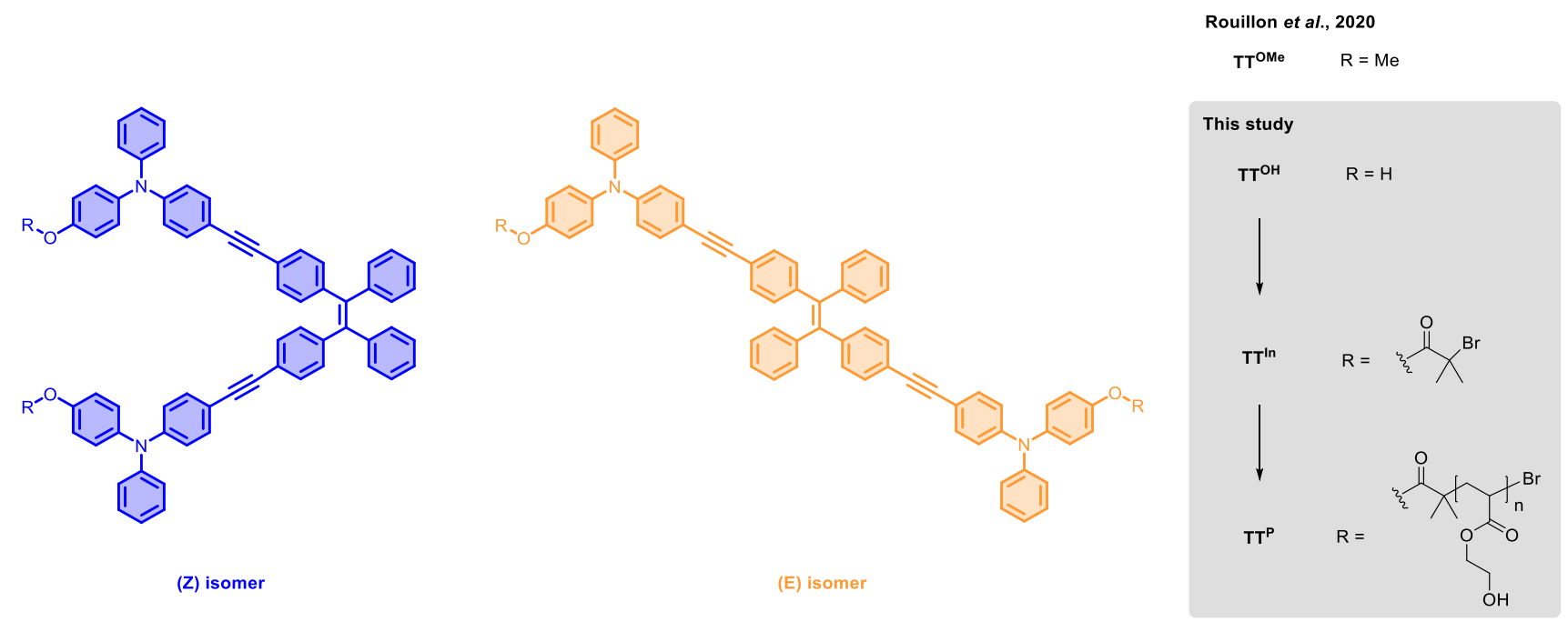

Figure 1. Chemical structure of $(\mathbf{E} / \mathbf{Z}) \mathbf{T T}^{\mathbf{P}}$ and its precursors.

well-suited for in vivo applications, ${ }^{34}$ while larger nanoparticles (> $100 \mathrm{~nm}$, typically) are rapidly cleared from the bloodstream upon internalization within macrophages and tend to induce more severe adverse effects such as acute inflammations. ${ }^{35}$

In this work, wishing to further explore extended TPE derivatives and taking advantage of our above-mentioned long-time expertise in the functionalization of lipophilic fluorophores through controlled radical polymerization, we have synthesized and studied $\mathbf{T T}^{\mathbf{P}}$ a new two-photon absorbing, water-soluble and AIE active luminescent probe, that can be derived into two stereoisomers differing by the stereoconfiguration of their central double bond (Fig. 1).

Through a combined study, involving DLS and DOSY NMR, we investigate the self-assembly process of both isomers and their mixture in aqueous suspension. In particular, we show that, owing to the amphiphilic macromolecular nature of the molecule, it is possible to obtain controlled small-sized ( $c$ a 10 $\mathrm{nm}$ ) nano-assemblies of the chromophores under either their $(\mathrm{Z})$ and (E) forms in both pure water and physiological media. The resulting colloidal suspensions combine significant two-photon absorption (2PA) cross sections and Aggregation-Induced Emission efficiencies, making them suitable for two-photon fluorescence microscopy in living biological systems. Comparison with our previously studied assemblies of pure nano-precipitated (E/Z)TT ${ }^{\text {OMe }}$ chromophores $^{32}$ on several days after injection into zebrafish embryos clearly demonstrated the benefits of polymer functionalization and underlined the biocompatibility of these resulting nano-objects.

\section{MATERIALS AND METHOS}

\section{Synthesis}

Syntheses were performed in oven-dried vessel purged with argon. Solvents were dried on $3 \AA$ molecular sieves. The reactions were monitored by analytical thin layer chromatography (TLC) on Merck 60 F-254 precoated silica gel plate (0.2 mm thickness) and product were revealed at UV lamp. Purification by column chromatography was made using over Mercksilica gel 60 $(0.040-0.063 \mathrm{~mm})$.
All newly synthesized compounds were routinely characterized by ${ }^{1} \mathrm{H}$ and ${ }^{13} \mathrm{C} \mathrm{NMR}$, and high-resolution mass spectrometry (HRMS). Detailed synthetic protocols and characterization data, including NMR spectra, are available as supplementary material (S1 and S2, Fig. S2-S15)

NMR studies

NMR spectra were recorded at room temperature on a Bruker Avance 400 functioning at $400 \mathrm{MHz}$. Chemical shifts are reported as values (ppm) with reference to the peak of $\mathrm{CDCl}_{3}$, DMSO-d6, or $\mathrm{D}_{2} \mathrm{O}$. Abbreviations for the ${ }^{1} \mathrm{H}$ NMR data are: chemical shift $\delta$, multiplicity $(\mathrm{s}=$ singlet, $\mathrm{d}=$ doublet, $\mathrm{t}=$ triplet, $\mathrm{q}=$ quartet, $\mathrm{m}=$ multiplet $)$, coupling constants $\mathrm{J}$.

Diffusion experiments were performed on a Bruker Avance III $400 \mathrm{MHz}$ spectrometer equipped with a Prodigy Cryoprobe. The temperature was regulated at $298 \mathrm{~K}$. A bipolar pulse longitudinal eddy current delay (BPPLED) pulse sequence was chosen, and the diffusion time was set to $250 \mathrm{~ms}$. Sine shaped pulse field gradient were used with a length of $2.5 \mathrm{~ms}$ and the gradient intensity was linearly incremented from 0.963 to $47.187 \mathrm{G} \mathrm{cm}$ 1 over 30 experiments. After each gradient pulse, a $200 \mathrm{~ms}$ delay was used as a recovery delay.

DOSY NMR were generally processed by Mestrelab MNova using bayesian transformation. Polydispersity of the polymer was determined thanks to the maximum entropy methodology, processed on NMRNotebook. ${ }^{36}$

Dynamic light scattering (DLS) was recorded with a Malvern Instruments Zetasizer nano series instrument (with solutions at constant $10^{-5} \mathrm{M}$ concentration).

HRMS measurements were performed at the Centre Commun de Spectrométrie de Masse (CCSM) of Lyon (France).

\section{Preparative separation of the $(E)$ and $(Z)$ isomers}

The separation of the $(\mathrm{E})$ and $(\mathrm{Z})$ isomers was done on the compound $(\mathbf{E} / \mathbf{Z}) \mathbf{T T}^{\text {In }}$ using a chiral stationary phase, an amylose tris-(3,5-dimethyl-phenylcarbamate). Sixty successive injections on Chiralpak IA $(250 \times 10 \mathrm{~mm})$, with hexane/2-PrOH/dichloromethane $(90 / 5 / 5)$ as mobile phase at $5 \mathrm{~mL} \cdot \mathrm{min}^{-1}$, allowed to obtain $29 \mathrm{mg}$ of the first eluted isomer, $(\mathbf{Z}) \mathbf{T T}^{\mathrm{In}}$, and $38 \mathrm{mg}$ 
of the second eluted isomer, (E)TT ${ }^{\text {In }}$ (Chromatograms on Fig. S16).

\section{Spectroscopic measurements}

Absorption spectra (UV-Vis) were recorded with a Jasco 670 spectrometer. Fluorescence spectra were performed on a Horiba Jobin-Yvon Fluorolog-3 spectrofluorometer. Spectra were reference-corrected for both the excitation source light intensity variation (lamp and grating) and the emission spectral response (detector and grating). Emission spectra were recorded at 350 $\mathrm{nm}$ as excitation wavelength. For the comparison of emission spectra of compound in various water/DMSO mixtures, spectra were normalized of their respective absorbance. Absolute fluorescence quantum yields were measured with a calibrated integrative sphere $(2 \pi$ steradians covered with spectralon $\AA$, model G8 from GMP) as described in the literature ${ }^{1}$. Each sample was placed on a quartz tube at the concentration of $2.10^{-5} \mathrm{M}$. Four measurements were made with constant excitation and emission to give four integrated intensities. $E_{c}$ and $E_{a}$ are integrated fluorescence spectra of direct excitation with and without the sample respectively. $L_{c}$ and $L_{a}$ are integrated excitation spectra of the sphere with and without the sample respectively. A density filter ( $f=0.5 \%$ ) was used to reduce the intensity of excitation profile. Quantum yield is calculated according to the equation (1):

$\Phi_{\text {fluo }}=\frac{\mathrm{E}_{\mathrm{c}}-\mathrm{E}_{\mathrm{a}}}{\mathrm{f}\left(\mathrm{L}_{\mathrm{a}}-\mathrm{L}_{\mathrm{c}}\right)}$

\section{Two-photon absorption cross sections measurements}

Two-photon excitation spectra of the studied compounds were measured by two-photon excitation-induced fluorescence technique in the 700-900 $\mathrm{nm}$ range. Excitation source was a tunable femtosecond Ti:sapphire laser (Chameleon Ultra I, Coherent). Laser beam was focused into a 10x10 cm quartz (QZS) cell using a $100 \mathrm{~mm}$ focal length lens. The cell containing the sample was positioned to minimize the optical path of the exciting laser and that of the emitted fluorescence in the sample thus minimizing inner filter effects and other artefacts. Emitted fluorescence was collected at $90^{\circ}$ with respect to the excitation, filtered by adapted low-pass filters and was detected by a fiber optic spectrometer (AvaSpec-EVO, Avantes).

Excitation power was measured by a thermal detector (S405C, Thorlabs). It was first verified that 2PA induced fluorescence showed quadratic excitation power dependence at $720 \mathrm{~nm}$ for all compounds. Then power was set to $40 \mathrm{~mW}$ for the measurement of the two-photon spectra. 2PA-induced fluorescence spectra did not show excitation wavelength dependence. Moreover, we checked in each case that the corrected fluorescence signal overlapped very well with the one-photon absorption (1PA) induced fluorescence spectra.

The 2PA cross sections were calculated based on the integration of the fluorescence signal, by comparison with that of a fluorescein solution $\left(10^{-5} \mathrm{~mol} / \mathrm{L}, \mathrm{pH} 13\right)$ as a $2 \mathrm{PA}$ standard, taken from the most recent literature. ${ }^{37}$

\section{Cell culture}

Human breast cancer cells MCF-7 (purchased from ATCC) were cultured in DMEM/F-12 medium with GlutaMAX ${ }^{\mathrm{TM}_{-} \mathrm{I}}$ (containing 4.5 g.L. $\mathrm{L}^{-1}$ of D-glucose) supplemented with $10 \%$ fetal bovine serum and $1 \%$ penicillin/streptomycin. Cells were grown at $37{ }^{\circ} \mathrm{C}$, in humidified atmosphere with $5 \% \mathrm{CO}_{2}$.

\section{Cytotoxicity study}

MCF-7 cells were seeded in 96-well plate, incubated with increasing concentrations (from 2.5 to $150 \mu \mathrm{g} \cdot \mathrm{mL}^{-1}$ ) of the different isomers for 3 days and the percentage of living cells was quantified by MTT assay. This consists in a colorimetric test performed using 3-(4,5-dimethylthiazol-2-yl)-2,5-diphenyltetrazolium bromide (Promega) where cells were incubated with $0.5 \mathrm{mg} \cdot \mathrm{mL}^{-1}$ MTT for $4 \mathrm{~h}$ to determine mitochondrial enzyme activity. Then, MTT precipitates were dissolved in $150 \mu \mathrm{L}$ ethanol/DMSO solution (in proportion 1/1) followed by $20 \mathrm{~min}$ of shaking and absorbance was read at $540 \mathrm{~nm}$. Cells treated with the vehicle were served as control.

\section{Imaging potential in vitro}

The cellular uptake experiment was performed using confocal fluorescence microscopy on living cells. Cells were seeded $\left(10^{6}\right.$ cells $\cdot \mathrm{cm}^{-2}$ ) on culture dishes with a glass bottom (Fluorodish from World Precision Instruments, Stevenage, UK). After seeding, cells were incubated with $50 \mu \mathrm{g} . \mathrm{mL}^{-1}$ of $(\mathrm{E})$ or $(\mathrm{Z})$ isomers for $24 \mathrm{~h}$. Cells were also loaded 15 min with CellMask ${ }^{\mathrm{TM}}$ (Invitrogen, Cergy Pontoise, France) at $5 \mu \mathrm{g} \cdot \mathrm{mL}^{-1}$, for membrane staining. Then, cells were washed twice with culture medium and fluorescence imaging was performed on living cells with a LSM780 LIVE confocal microscope (Carl Zeiss, Le Pecq, France), at $750 \mathrm{~nm}$ for isomers detection and $561 \mathrm{~nm}$ for cell membranes. All images were obtained with a high magnification (Plan-Apochromat 40x/1.3 Oil DIC).

\section{Zebrafish breeding}

Casper zebrafish embryos were purchased from Zebrafish International Resource Center (ZIRC) and raised to adulthood in circulating aquarium system at $28{ }^{\circ} \mathrm{C}$ and $14 \mathrm{~h} \mathrm{light} / 10 \mathrm{~h}$ dark cycle, in the Molecular Mechanisms in Neurodegenerative Dementia (MMDN) laboratory (Inserm U1198), Montpellier University. Experiments with zebrafish embryos are performed according to the EU Directive 2010/63/EU on the protection of animals used for scientific purposes.

\section{Imaging on Casper zebrafish embryos}

Casper zebrafish embryos of $72 \mathrm{~h}$ post fertilization (hpf) were intravenously injected with $10 \mathrm{~nL}$ of $(\mathrm{Z})$ or $(\mathrm{E})$ isomer at $1 \mathrm{mg}$ $\mathrm{mL}^{-1}$ concentration $(\mathrm{n}=7$ for control, $\mathrm{n}=9$ for $(Z)$ isomer, $\mathrm{n}=$ 10 for (E) isomer). One hour after injection, embryos were observed using one-photon excitation microscope at excitation wavelength of 340-380 $\mathrm{nm}$, and after embryos were observed using two-photon excitation confocal microscopy at excitation wavelength of $750 \mathrm{~nm}$.

\section{Toxicity study on zebrafish embryos}

After injections, embryos were then maintained 3 days in breeding conditions to analyze every day the biocompatibility of (Z) isomer and $(\mathrm{E})$ isomer according to various parameters relating the good development of embryos, such as mobility, heart rate, malformations and deaths. 


\section{RESULTS AND DISCUSSION}

\section{Synthesis}

All molecules discussed in the following are presented in Figure 1. Synthesis of the $(\mathbf{E} / \mathbf{Z}) \mathbf{T} \mathbf{T}^{\mathrm{In}}$ macroinitiator was adapted from the method previously published by us for the $(\mathbf{E} / \mathbf{Z}) \mathbf{T T}^{\mathbf{O M e}}$ molecule ${ }^{32}$ keeping here the phenolic function free from the beginning (Fig. S1, detailed synthetic procedures available as supplementary materials, S1). Thus, Buchwald-Hartwig coupling between 4-hydroxydiphenylamine and para-bromo-iodobenzene was achieved with a good yield to afford 4-bromo-N-(4-hydroxyphenyl)diphenylamine (1), thanks to a procedure that made it compatible with the presence of the free phenolic moieties. ${ }^{38}$

Then, a palladium catalyzed Sonogashira cross-coupling with (triisopropylsilyl)acetylene yielded alkyne 2, which was in turn deprotected with TBAF. The instable free alkyne as obtained was directly engaged in Sonogashira coupling with TPE-Br to lead to $(\mathbf{E} / \mathbf{Z}) \mathbf{T T}^{\mathbf{O H}}$. Finally, esterification between the (E/Z)TT Th $^{\mathbf{O H}}$ diol and 2-bromo-2-methylpropionyl leads to the target macroinitiator $(\mathbf{E} / \mathbf{Z}) \mathbf{T} \mathbf{T}^{\mathbf{I n}}$. This synthesis being non-stereoselective, separation of the macroinitiator diastereoisomers was required to afford stereopure versions of the chromophore. It was herein performed on amylose-based chiral stationary phase (Fig. S16), which efficiency has already been demonstrated by us on similar chromophores. ${ }^{32}$

The controlled polymerizations of $(\mathbf{E} / \mathbf{Z}) \mathbf{T T}^{\mathrm{In}}$ as a (E/Z)-mixture, and also in stereopure form, were carried out in bulk 2hydroxyethyl acrylate (HEA) monomer, using 2,2'-bipyridine and copper(I) bromide as a catalytic system, as already described in previous reports for the elaboration of related polymer-chromophore adducts. ${ }^{15-18}$ The characteristic signatures of the aromatic part of the ${ }^{1} \mathrm{H}$ NMR spectra confirm that stereopurity has been preserved after the ATRP reaction and purification (Fig. S13). In all polymerization cases reported herein, a rigorous control of the polymerization kinetics makes it possible to obtain a range of target chain lengths in a controlled manner with low polydispersity (vide infra) which is essential for the comparison of the systems.

\section{Spectroscopic studies}

Then, the spectral features of $(\mathbf{E} / \mathbf{Z}) \mathbf{T T}^{\mathbf{P}}$ were studied in DMSO. The absorption and emission spectra are presented in Figure 2, while main spectroscopic data are gathered in Table 1. First, we notice that the spectral signatures of (E/Z)TT ${ }^{\mathbf{P}}$ (Fig. 2) correspond well to those observed for their parent monomeric equivalent (E/Z)T $\mathbf{T}^{\mathbf{O M e}}$ which can be summarized as follows: (i) a structureless ICT band, typical of large $\pi$-conjugated system; (ii) large Stokes shift ( $\mathrm{ca} 6500 \mathrm{~cm}^{-1}$ ) indicating large reorganization processes between ground and excited electronic states; (iii) an absorption band of the (Z)-isomer slightly blue-shifted $\left(\lambda_{\mathrm{abs}}=357 \mathrm{~nm}\right)$ with respect to $(\mathrm{E})$-isomer $\left(\lambda_{\mathrm{abs}}=374 \mathrm{~nm}\right)$, and a reversed behavior for the emission with $\lambda_{\mathrm{em}}=543 \mathrm{~nm}$ for the (Z)-isomer, $530 \mathrm{~nm}$ for the (E)-isomer of $\mathbf{T T}^{\mathbf{P}}$; (iv) a similar two-photon absorption cross section $\sigma_{2 \mathrm{PA}}$ for the (Z)-isomer as for the (E)-isomer (140 vs. $100 \mathrm{GM}$ ) in the same range of wavelengths maxima ( $c a 710 \mathrm{~nm}$ ). Consequently, functionalization of this chromophore with the polymeric PHEA chains does not markedly affect its main spectroscopic characteristics in DMSO solutions. a)

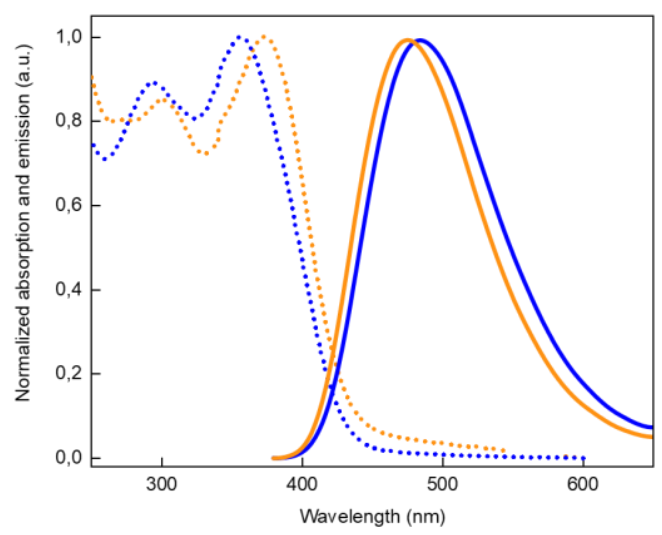

b)

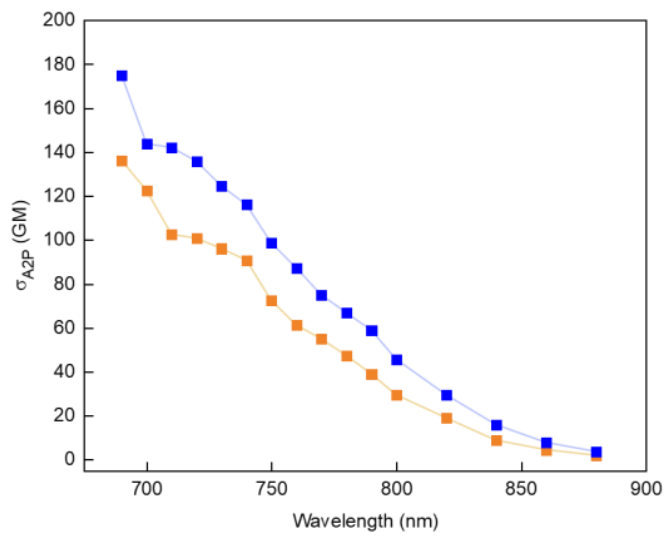

Figure 2. a) Absorption (dashed) and emission (solid lines) spectra of the (E)-isomer (yellow) and (Z)-isomer (blue) of TT $^{\mathbf{P}}$ in DMSO b) TPFE spectra of the (E)-isomer (yellow) and (Z)-isomer (blue) of $\mathbf{T T}^{\mathbf{P}}$ in DMSO.

Table 1. Spectroscopic properties of $\mathrm{TT}^{\mathrm{P}}$ isomers in solution in DMSO.

\begin{tabular}{lll}
\hline & $(\mathrm{Z}) \mathrm{TT}^{\mathrm{P}}$ & $(\mathrm{E}) \mathrm{TT}^{\mathrm{P}}$ \\
\hline$\lambda_{\text {abs }}(\mathrm{nm})$ & 357 & 374 \\
$\lambda_{\mathrm{em}}(\mathrm{nm})$ & 480 & 477 \\
$\begin{array}{l}\text { Stokes shift }\left(\mathrm{cm}^{-}\right. \\
\left.{ }^{1}\right)\end{array}$ & 7200 & 5800 \\
$\Phi_{\mathrm{f}}$ & 0.025 & 0.018 \\
$\begin{array}{l}\sigma_{2 \mathrm{PA}}(\mathrm{GM}) \\
(\mathrm{nm})]\end{array}$ & $140[710]$ & $100[710]$ \\
\hline
\end{tabular}

The fluorescence quantum yields $\Phi_{\mathrm{f}}$ of $\mathbf{T T}^{\mathbf{P}}$ (stereopure $\mathrm{Z}$ and $\mathrm{E}$ form, and (E/Z) mixture) were also first estimated in DMSO solution, with the aim to highlight the influence of the polymerization degree on this parameter. Indeed, while the quantum yield of the macroinitiator $\left(\mathrm{n}=0\right.$ in Fig. S17) is $c a \Phi_{\mathrm{f}}=0.004$, 
the addition of polymer chains leads to a moderate yet significant improvement to reach $\Phi_{\mathrm{f}}=0.07$, a value that subsequently remained constant, within experimental error, for polymer chain lengths between 7 and 70 monomer units (Fig. S17). Thus, while the introduction of polymer chains seems to favor the emission (probably owing to steric-induced restriction of the rotation around the central double, a well-known mechanism in viscosity probes ${ }^{39}$ ) the effect quickly saturates as the polymer chain is extended, and emission quantum yield subsequently becomes independent on the length of the PHEA chains. In the rest of this study, we chose to focus on $(\mathbf{E} / \mathbf{Z}) \mathbf{T T}^{\mathbf{P}}$ with an average polymer chain length $n=16$ (Fig S14), which offers good dispersibility in aqueous media with a limited impact on the molecular weight of the chromophore.

The spectroscopic properties of the PHEA polymers in aqueous media were then studied in DMSO/water mixtures with increasing water volumic fraction (Fig. 3). For a volumic fraction in water $\mathrm{f}_{\mathrm{H} 2 \mathrm{O}}$ lower than $50 \%$, emission properties of $(\mathbf{E} / \mathbf{Z}) \mathbf{T T}^{\mathbf{P}}$ remain virtually constant with $\Phi_{\mathrm{f}} \approx 0.07$. For $\mathrm{f}_{\mathrm{H} 2 \mathrm{O}}$ above $50 \%$, a hypsochromic shift from 520 to $467 \mathrm{~nm}$ is noticed, consistent with that observed for the parent monomeric fluorophore in

a)

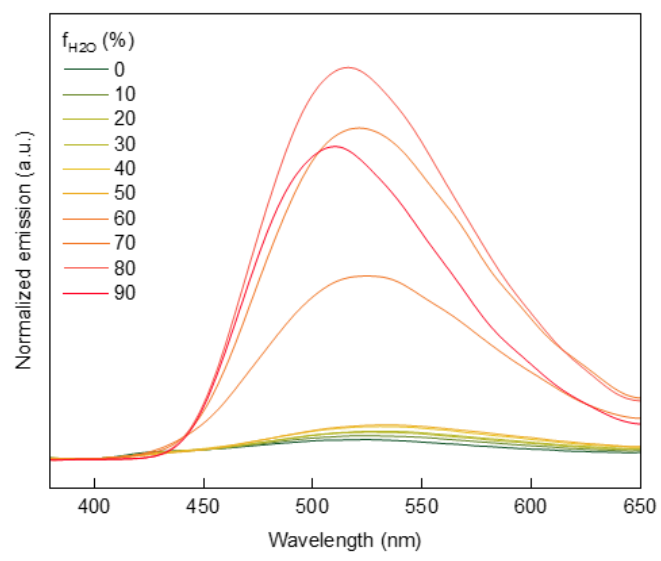

c)

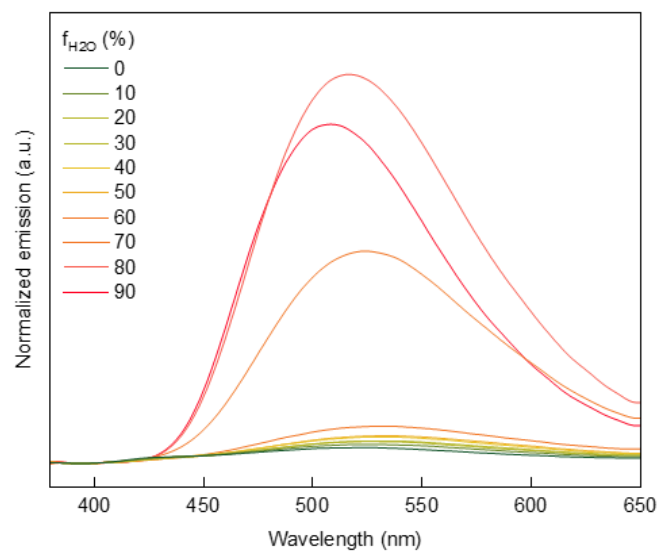

similar conditions; this is accompanied by a marked and progressive increase in $\Phi_{\mathrm{f}}$ with further addition of water, to reach a maximal $\Phi_{\mathrm{f}}=0.35$ for a $\mathrm{f}_{\mathrm{H} 2 \mathrm{O}}$ of $80 \%$. These two properties (hypsochromic shift and $\Phi_{\mathrm{f}}$ increase) are compatible with the hypothesis of a restriction of the rotation phenomena around the central double bond ${ }^{40}$ resulting from interchromophore aggregation in aqueous media. Thus, in contrast with previously reported similar chromophore polymer adducts, ${ }^{15-18}$ the presence of the water-solubilizing chains do not suffice to avoid molecular aggregation of $(\mathbf{E} / \mathbf{Z}) \mathbf{T T}^{\mathbf{P}}$ at high water contents, and the molecules self-assemble into nano-aggregates.

Similar evolution patterns are observed for the AIE properties of the pure $(\mathrm{E})$ and $(\mathrm{Z})$ isomers of $\mathbf{T} \mathbf{T}^{\mathbf{P}}$, although precipitation onset is shifted to $\mathrm{f}_{\mathrm{H} 2 \mathrm{O}} \mathrm{ca} 60 \%$. At $\mathrm{f}_{\mathrm{H} 2 \mathrm{O}}$ of $90 \%$, the fluorescence quantum yields of $(\mathrm{Z})$ and $(\mathrm{E})$ isomers reach a maximal $\Phi_{\mathrm{f}}=$ 0.38 and 0.37 respectively. These values, similar to those observed with the (E/Z) mixture of $\mathbf{T} \mathbf{T}^{\mathbf{P}}$, are however significantly lower than the values reached in their parent stereopure monomeric analogues in nano-suspensions. ${ }^{32}$

This similarity of AIE properties between the stereopure versions and the mixture of $(\mathbf{E} / \mathbf{Z}) \mathbf{T T}^{\mathbf{P}}$ thus suggests that the nature of the supramolecular assemblies formed in the case of PHEA

b)

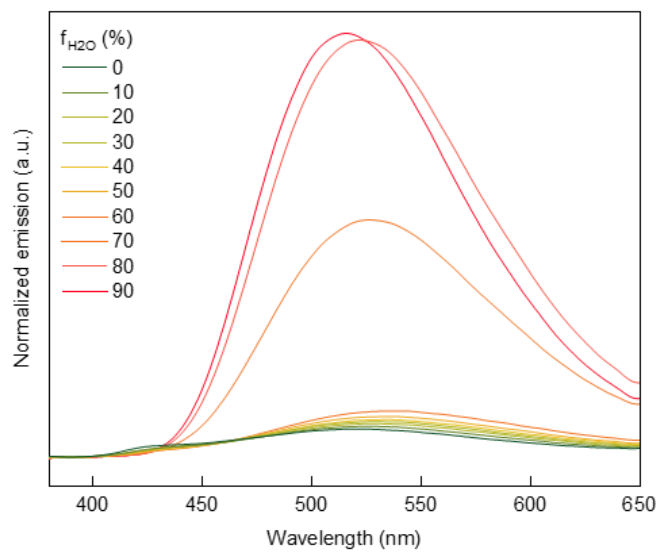

d)

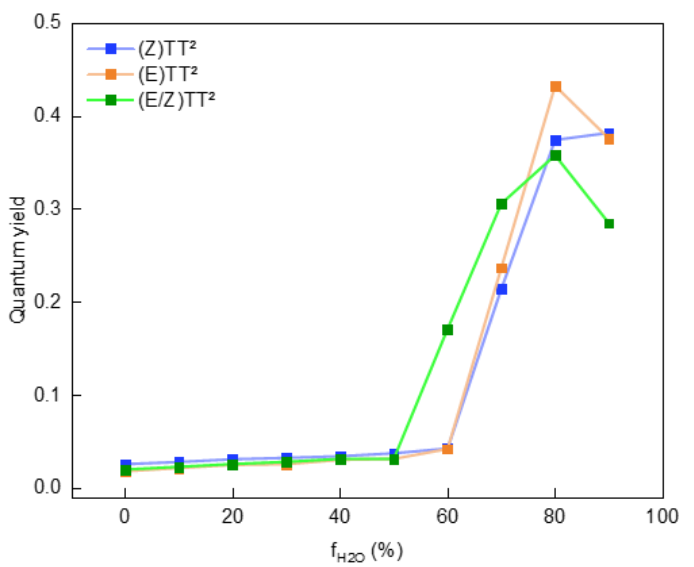

Figure 3. Emission of a) the isomers mixture, b) the Z-isomer and c) the E-isomer of $\mathbf{T T}^{\mathbf{P}}$ in various water/DMSO mixtures. d) Evolution of the fluorescence quantum efficiency of the isomers mixture (green), (Z) isomer (blue) and (E) isomer (yellow) of $\mathbf{T T}^{\mathbf{P}}$ in various water/DMSO mixtures. 


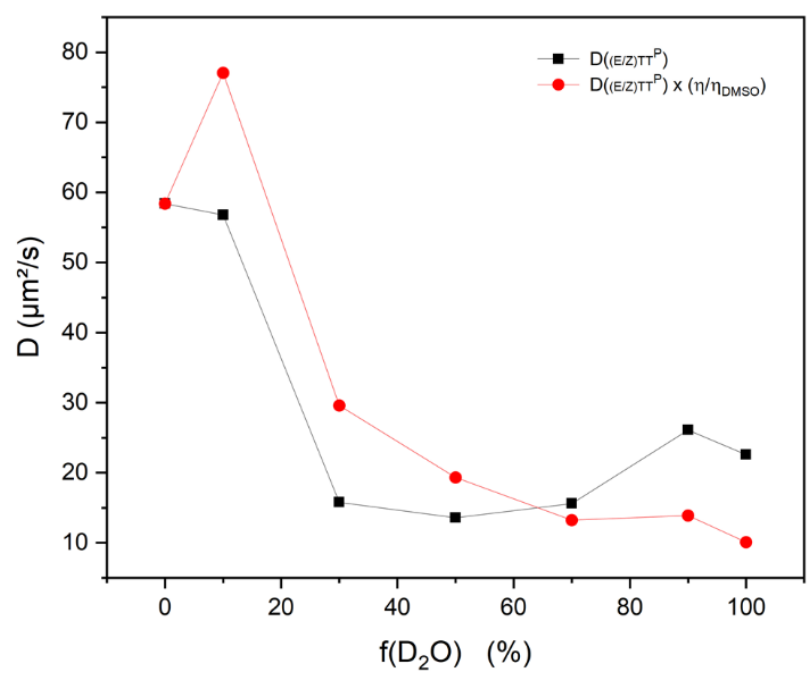

Figure 4. Evolution of the diffusion coefficient of D(E/Z)TTP (black) and of the viscosity-corrected D $\eta$ (red) diffusion coefficient of $(\mathbf{E} / \mathbf{Z}) \mathbf{T T}^{\mathbf{P}}$ in $\mathrm{D}_{2} \mathrm{O} / \mathrm{DMSO}-\mathrm{d} 6$ mixture with increasing $\mathrm{D}_{2} \mathrm{O}$ contents.

chain chromophores does not markedly depend on the stereochemistry of the chromophores. This strikingly differs from our recent observation on similar AIEgens devoid of PHEA side substituents, where the higher crystallinity of the stereopure sample clearly benefited the AIE. In other words, this suggests that, quite expectedly, the presence of the PHEA chain influences the chromophore packing in the nano-assemblies.

NMR study of (E/Z)TT ${ }^{\mathrm{P}}$

To gain understanding on the nature of the interactions between $(\mathbf{E} / \mathbf{Z}) \mathbf{T T}^{\mathbf{P}}$ polymers as a function of $\mathrm{f}_{\mathrm{H} 2 \mathrm{O}}$, and the characteristic size of their assemblies, NMR experiments were then performed in different $\mathrm{D}_{2} \mathrm{O}$ / DMSO-d6 mixtures.

As a first notice, ${ }^{1} \mathrm{H}$ NMR spectra reveal a peculiar evolution of the signal belonging to the chromophoric part and the polymer chains upon increasing of $\mathrm{f}_{\mathrm{D} 2 \mathrm{O}}$ (Fig. S15). Indeed, while the signals of the polymer chains remain constant in width and intensity, both the aromatic signals of the chromophore (between 6.80 and $7.45 \mathrm{ppm}$ ) and the signal of the two methyl end chains (1.24 ppm) broaden and decrease drastically with increasing the water fraction. At $\mathrm{f}_{\mathrm{D} 2 \mathrm{O}}$ as low as $10 \%$, these are already hardly distinguishable from the baseline and are no longer visible at $\mathrm{f}_{\mathrm{D} 2 \mathrm{O}}=50 \%$. It would thus seem that aggregation phenomena between the hydrophobic parts of the core (chromophore and attached initiator group) take place in an aqueous medium, in agreement with the spectroscopic evolutions observed. Again, this evolution contrasts strongly with previous examples of similar polymer appended chromophores reported by us, ${ }^{17}$ where the relative intensity of the different peaks was unchanged between DMSO-d6 and $\mathrm{D}_{2} \mathrm{O}$ media, characteristic of individual macromolecular objects in solution. Such a behavior is classically observed and has been studied in depth in the past during the self-aggregation process of conjugated polymer such as polythiophenes. ${ }^{41}$ It indicates here that, like in the latter, $\pi$-stacking constitutes unsurprisingly the main driving force for the selfassembly of the polymer chains.
To investigate this aggregation phenomenon, and its dependence on medium composition and chromophore stereoconfiguration, 2D diffusion-ordered NMR spectroscopy (DOSY) was then used (available as Supplementary Materials S3, Fig. S18S29).

First, in pure DMSO-d6 solution, DOSY was used to verify that $(\mathbf{E} / \mathbf{Z}) \mathbf{T T}^{\mathbf{P}}$ molecules were present as individual polymer chains, and to determine their associated polydispersity index (Đ). thanks to the methodology initially developed by Delsuc et al. and tested in the past on similar polymers. ${ }^{36,42}$

In the case of all samples studied herein, the NMR signals attributed to $(\mathbf{E} / \mathbf{Z}) \mathbf{T T}^{\mathbf{P}}$ belong to the same polymer species (with a single diffusion constant Fig, S18). Polydispersity index determination provides a value for $\mathrm{Ð}=1.22$ which, although in the high range of what is usually achieved by ATRP, appears satisfactory considering our previous results. ${ }^{16-17}$

In each solvent, diffusion coefficient values $\mathrm{D}$ of a molecule, macromolecule or nano-object relates to the gyration radius of the latter, considered as a random coil: thus, comparison of the $\mathrm{D}$ values obtained for the $(\mathrm{Z})$ and $(\mathrm{E})$ isomers of $\mathbf{T T}^{\mathbf{P}}$ featuring similar polymer side chain lengths brings valuable information regarding the impact of stereochemistry on the characteristic dimensions of the associated coil. In DMSO-d6 solution, similar mean diffusion coefficients are monitored for the $(\mathrm{Z})$ and $(\mathrm{E})$ isomers (59 and $52 \mu \mathrm{m}^{2} / \mathrm{s}$ respectively), characteristic of a comparable mobility and size for both solvated molecules (Fig. S19 and S20). As expected, the average diffusion coefficients D are smaller in $\mathrm{D}_{2} \mathrm{O}$, as a consequence of the aggregation process, yet similar for each isomer ( 25 for the (E) isomer and $26 \mu \mathrm{m}^{2} / \mathrm{s}$ for (Z) isomer, Fig. S21 and S22). This indicates a similar nature for the small-sized nano-objects formed by molecular aggregation in the case of both stereoconfigurations.

Wishing to get more insight into the aggregation processes taking place at high water contents, we then monitored in a next series of experiments the evolution of the $\mathrm{D}_{(\mathrm{E} / \mathrm{Z}) \mathrm{TT}}{ }^{\mathrm{P}}$ coefficients as a function of $\mathrm{f}_{\mathrm{D} 2 \mathrm{O}}$ (Fig. 4, Table $\mathrm{S} 1$ ). Since the spectroscopic studies had already underlined that the stereopurity had only little impact on the AIE properties, this study was limited to the (E/Z) mixture of $\mathbf{T T}^{\mathbf{P}}$, available in larger quantities (as typically required for DOSY analyses) than its stereopure analogues. First, a global very noticeable decrease of $D_{(E / Z) T T}{ }^{P}$ values could be qualitatively observed upon increasing the water fraction from the initial pure DMSO sample, in agreement with the suspected aggregation process (Figs S23-S29). However, when comparing systems in different solvents compositions, diffusion coefficient of a given object does not solely depend on its radius, but also critically on the viscosity of the medium: it is well documented that the latter varies strongly in DMSO/water mixtures depending on the ratio of each solvent. In order to discriminate between both contributions, it is possible and beneficial to use a viscosity-corrected diffusion coefficient. Recent studies have indeed highlighted that, providing that polymer concentration was kept low in the medium ( $c a 1 \mathrm{mg} / \mathrm{mL})$, using such viscosity-corrected values for the diffusion signal allowed a precise evaluation and comparison of macromolecules dimensions even in solvents possessing very different intrinsic viscosities. $^{43}$ 
We thus considered in a next step the variations of a corrected diffusion coefficient defined, for each composition $\mathrm{f}_{\mathrm{D} 20}$ by equation 2:

$$
\left.D_{\eta}=D_{(E / Z) T T^{P}} \frac{\eta}{\eta_{D M S O}} 2\right)
$$

With the viscosity $\eta$ (mPa.s) of the DMSO/water mixture of the considered sample, ${ }^{44} \eta_{D M S O}$ the viscosity of pure DMSO.

Using this viscosity corrected diffusion coefficient we notice for $\mathrm{f}_{\mathrm{D} 20}>10 \%$, a progressive decrease in the corrected diffusion coefficient $D_{\eta}$ as $f_{D 20}$ is increased (Fig. 4, Table $S 1$ ). This confirms that a progressive aggregation process occurs, and that the average size of the resulting nano-aggregates gets bigger and reaches a maximal size in pure water, in agreement with the observed AIE evolution.

Stokes-Einstein equation relates the diffusion coefficient $\mathrm{D}$ of a well-defined spherical nano-object to its radius $\mathrm{r}$, according to equation (3):

$\mathrm{D}=\frac{k_{b} T}{6 \pi \eta r}$

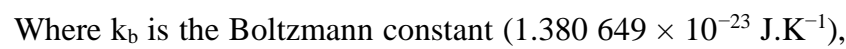
$\mathrm{T}$ the temperature in Kelvins (here taken as $298 \mathrm{~K}$ ) and $\eta$ the dynamic viscosity, in Pa.s. The latter is well known and has been tabulated in the past for different DMSO/water mixtures. ${ }^{44}$

Using these tabulated values, we calculated a nanoparticle radius (considered as rigid spheres) $c a 7 \mathrm{~nm}$ in DMSO:water, 70:30 (v/v, corresponding to the onset of the self-assembly process). In pure water, it culminates to about $9 \mathrm{~nm}$, i.e. a diameter of about $18 \mathrm{~nm}$, in the spherical assumption.

\section{Dynamic Light Scattering (DLS) study}

Although DOSY NMR brings conclusive evidence for the formation of nanoparticles by self-assembly of $(\mathbf{E} / \mathbf{Z}) \mathbf{T T}^{\mathbf{P}}$ at high water content, extrapolation of the characteristic size of the nano-objects diffusion coefficient is inherently prone to error, specifically for non-rigid and non-perfectly spherical nano-objects. ${ }^{45-46}$ In order to get additional and complementary insight on the dimension of the self-assembled nanoparticles, DLS experiments were thus undertaken on the aqueous suspensions of $(\mathbf{E} / \mathbf{Z}) \mathbf{T T}^{\mathrm{P}}$. As expected, no scattering signal was obtained for the initial solution of the (E/Z) mixture of $\mathbf{T} \mathbf{T}^{\mathbf{P}}$ in DMSO. In contrast, reliable DLS correlogram could not be obtained for both isomers (Fig. 5), with $\mathrm{f}_{\mathrm{H} 2 \mathrm{O}}<70 \%$. Again, in contrast with what had been noticed in our previous work with the monomeric analogues $(\mathbf{E} / \mathbf{Z}) \mathbf{T T}{ }^{\mathbf{O M e}}$, where nano-precipitation in water resulted in the formation of particles with a 150-200 nm average diameter, ${ }^{32}$ an homogeneous suspension of small nanoparticles was observed here: for $\mathrm{f}_{\mathrm{H} 2 \mathrm{O}}=70 \%, \mathrm{~d}=25 \mathrm{~nm}(\mathrm{PDI}=$ $0.29)$ and $\mathrm{f}_{\mathrm{H} 2 \mathrm{O}}=90 \%, \mathrm{~d}=26 \mathrm{~nm}$.(PDI $=0.28$; Fig. 5). Then, upon simple mixing of the dry polymeric materials in pure distilled water, this average size is halved (around $10 \mathrm{~nm}$ for $(\mathbf{E} / \mathbf{Z}) \mathbf{T T}^{\mathbf{P}}$; PDI $\left.=0.42\right)$ and slightly larger nano-suspensions are observed for the (E) isomer compared to (Z) $(12$ vs. $10 \mathrm{~nm})$. a)

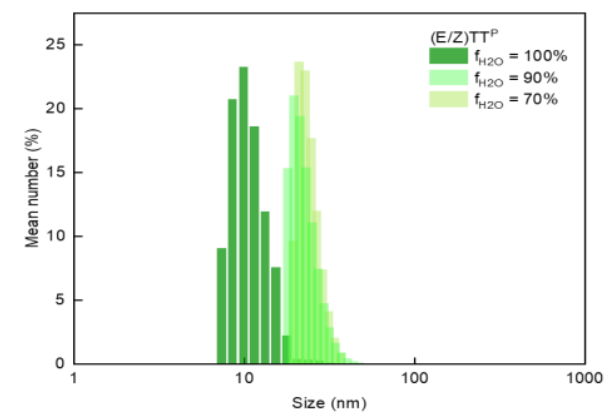

b)

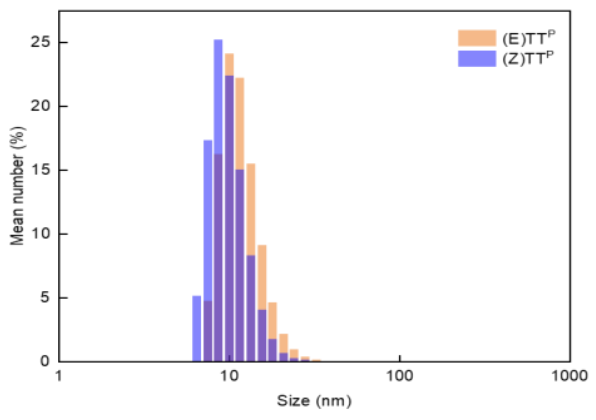

Figure 5. DLS of a) (E/Z) mixture of $\mathbf{T T}^{\mathbf{P}}$ in water/DMSO mixtures and b) stereopure $\mathbf{T T}^{\mathbf{P}}$ in water.

This result indicates that, as expected, the bolaamphiphilic nature of our polymer appended chromophore favors the controlled formation of small and monodisperse nano-objects, which size seems ideally suited for bio-related applications.

\section{Biological studies}

In a previous report, we showed that suspensions of non-polymeric (E/Z) T T ${ }^{\mathbf{O M e}}$ were efficient in providing highly contrasted two-photon fluorescence microscopy images, both in cellulo and in vivo (after injection in the caudal vein of zebrafish embryos). However long-term following of the fate of the zebrafish embryos revealed that various malformations and premature death occurred within the days after injections, raising important issues regarding the biocompatibility of these nano-objects. Size and surface functionalization of nanoparticles are indeed two important parameters that largely determine their fate and biocompatibility in living systems, both of which turned out to be suboptimal in this initial works.

Since our present study allowed us to underline several promising features of $(\mathbf{E} / \mathbf{Z}) \mathbf{T} \mathbf{T}^{\mathbf{P}}$ as potential two-photon luminescent contrast agent, we decided to further investigate that point using similar setups and biological systems as in our abovementioned work. More specifically we aimed at establishing whether the adjunction of polymer side substituents and the resulting impact on the features of the self-assembled nano-systems could be beneficial in terms of biocompatibility.

In a first step, we have studied the biocompatibility of such compounds on human cells in culture. The goal was to deter 
a)

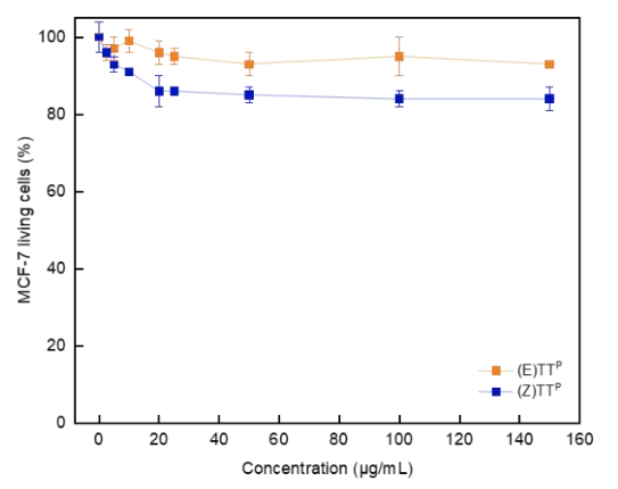

b)

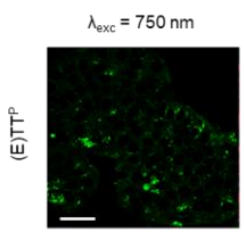

CellMask
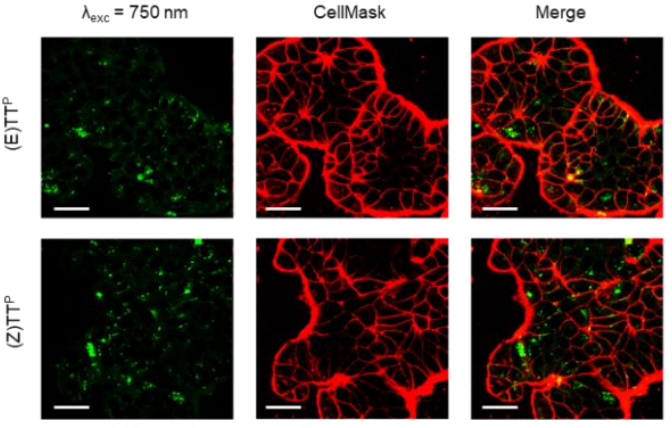

Figure 6. In cellulo studies a) Cytotoxic study of $\mathrm{E}$ and $\mathrm{Z}$ isomers. Increasing concentrations (from 2.5 to $150 \mu \mathrm{g} . \mathrm{mL}^{-1}$ ) of compounds were incubated with MCF-7 cells for 3 days and the percentage of living cells was quantified by MTT assay. b) Confocal microscopy imaging of living MCF-7 cells after $24 \mathrm{~h}$ incubation with $50 \mu \mathrm{g} . \mathrm{mL}^{-1}$ of $\mathrm{E}$ or $\mathrm{Z}$ isomers (green dots). Isomers were revealed by two-photon excitation at $\lambda_{\mathrm{exc}}=750 \mathrm{~nm}$ (Chameleon, LSM 780) and cell membranes (red outlines) were stained with orange CellMask $\left(\lambda_{\mathrm{exc}} / \lambda_{\mathrm{em}}=554 / 567 \mathrm{~nm}\right)$. Scale bars $=10 \mu \mathrm{m}$.

mine which maximal concentration could be used while avoiding any significant cell death. To that end, increasing concentrations of compound in its isomeric $(\mathrm{Z})$ and $(\mathrm{E})$ form, were incubated with MCF-7 cells for 3 days. The result reported in figure 6 a suggested that, even at such high concentrations as 150 $\mu \mathrm{g} . \mathrm{mL}^{-1}$, both compounds were safe for the cell. In figure $6 \mathrm{~b}$, we can see that both compounds are highly luminescent (green dots) and efficiently internalized in the cancer cells, which plasmatic membranes are stained with cell mask (in red). In this experiment, isomers in living cells were revealed by two-photon excitation at $750 \mathrm{~nm}$ excitation wavelength. This imaging potential seems very similar to those obtained in our previous report on $(\mathbf{E} / \mathbf{Z}) \mathbf{T T} \mathbf{T}^{\text {OMe }}$.

Then, to determine the possibility for biomedical use, the imaging potential was analyzed in vivo, in zebrafish embryos. After injection in the caudal vein, $\mathbf{T T}^{\mathbf{P}}$, either in its $\mathrm{E}$ or $\mathrm{Z}$ form, provide high luminescence signal visible under UV-light excitation (pseudocolor green, Fig. 7) and exhibits a high solubility and bioavailability in all the organism. Importantly, the luminescence of these compounds was also investigated in two-photon microscopy conditions under pulsed laser excitation (Fig. 7b) a)

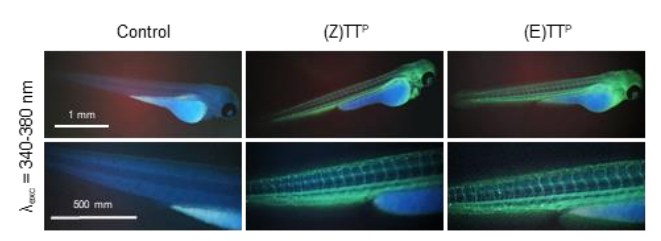

b)

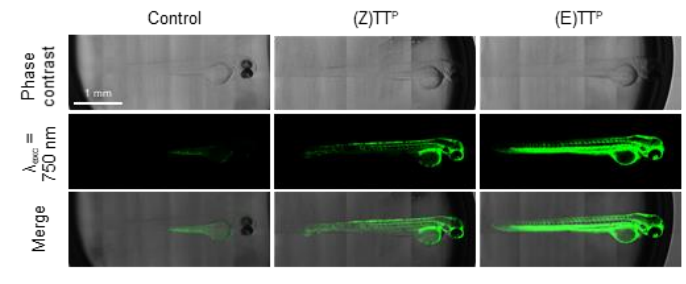

c)

\begin{tabular}{cccc}
\hline Toxicity study & Control $(n=7)$ & $(\mathrm{Z}) \mathrm{TTP}^{\mathrm{P}}(\mathrm{n}=9)$ & $(\mathrm{E}) \mathrm{TTP}^{\mathrm{P}}(\mathrm{n}=10)$ \\
\hline Movements & +++ & +++ & +++ \\
Stable heart rate & +++ & +++ & +++ \\
Malformations & -- & -- & -- \\
Deaths & -- & -- & -- \\
\hline
\end{tabular}

Figure 7. In vivo studies. Casper zebrafish embryos of $72 \mathrm{hpf}$ were intravenously injected with $10 \mathrm{~nL}$ of $\mathbf{T} \mathbf{T}^{\mathbf{P}}$ (isomer $\mathrm{Z}$ or isomer $\mathrm{E}$ in their pure form) at $1 \mathrm{mg} \cdot \mathrm{mL}^{-1}$ concentration. One hour after injection, embryos were observed using a) one-photon excitation microscopy at 340-380 nm and b) two-photon excitation microscopy at $750 \mathrm{~nm}$. c) Embryos were then maintained 3 days in breeding conditions to analyze every day the biocompatibility of $\mathrm{Z}$ isomer and $\mathrm{E}$ isomer according to the parameters reported in the table, with "+" for presence and "-" for absence.

strong capability of imaging was observed when excited at 750 $\mathrm{nm}$, similar to that achieved in our aforementioned report. ${ }^{32}$

In parallel, the biocompatibility of both isomers injected in the blood stream of embryos was studied. For 3 days, embryos development, rate heart and their mobility were daily monitored. The data reported in the table (Fig. 7c) demonstrate for both isomers that no toxicity could be detected in zebrafish embryos in the studied conditions, translating into no increase in the mortality of the said embryos. Survival and development of the zebrafish embryos, as monitored over several days, are indeed perfectly similar in the treated and control embryos. These results constitute a marked improvement in comparison with our recently published results with nano-precipated assemblies of $\mathbf{T T}^{\mathbf{O M e}}$ chromophores and highlight the strong potential of $\mathbf{T T}^{\mathbf{P}}$ for long term bioimaging of living organisms.

\section{CONCLUSIONS}

In this paper, we illustrate the benefits in functionalizing TPE based AIEgens, which structure is specifically optimized for two-photon induced emission properties at the solid state, with 
hydrophilic side polymer chains. In DMSO, the resulting bolaamphiphilic macromolecular chromophores $(\mathbf{E} / \mathbf{Z}) \mathbf{T T}^{\mathbf{P}}$ exist as individual, low-emissive $\left(\varphi_{\mathrm{f}} \approx 0.07\right)$ polymer chains. This is attested by DOSY NMR experiments, which indicate that, for both the $(\mathrm{Z})$ and $(\mathrm{E})$ isomers, a similar length of the polymer arms ( $\mathrm{n}=16$ units) and a similar low polydispersity $(\mathrm{Ð}=1.22)$ can be achieved, in agreement with the controlled nature of the radical polymerization.

In contrast, when dispersed in water, either from nano-precipitation of a concentrated solution of the molecule in DMSO or by direct mixing of the polymer powder in pure water or physiological solution, a characteristic AIE phenomenon is observed which correlates to the formation of small nano-bundles of several chromophore units of (E/Z)TT ${ }^{\mathbf{P}}$. DLS analyses carried out on both the $(\mathrm{Z})$ and $(\mathrm{E})$ isomers confirm the presence of nanoaggregates at $\mathrm{f}_{\mathrm{H} 2 \mathrm{O}}>0.5$, with a mean size $c a$. $10-15 \mathrm{~nm}$ and a low dispersity. To refine our understanding of the aggregation process dynamics, DOSY experiments over the whole range of $\mathrm{f}_{\mathrm{H} 20}$ gave additional insight on the formation of these aggregates. The latter is characterized by a progressive restriction in the measured diffusion coefficient for chemical shifts belonging to the polymer chain upon increasing $\mathrm{f}_{\mathrm{H} 20}$, to reach its lowest value in pure water, confirming that a self-assembly process drives the formation of the fluorescent organic nanoparticles. It is thereby confirmed that the strategy introduced herein is efficient in yielding ultra-bright, two-photon active organic nanoparticles with size optimized in regard with the target biological applications.

To illustrate the benefits of our approach in the specific framework of intravital bioimaging, the resulting aqueous suspension of both $(\mathrm{Z})$ and $(\mathrm{E}) \mathbf{T T}^{\mathbf{P}}\left(\mathrm{f}_{\mathrm{H} 20}=100 \%\right)$ were used as nano-sized fluorescent organic nanoparticle contrast agents in epifluorescence and two-photon fluorescence microscopy of the vascular systems of zebrafish embryos. Besides the favorable spectroscopic properties of the nano-objects, which afforded in all cases highly contrasted images, a distinctive advantage of the polymer functionalized two-photon AIEgens reported herein in comparison with their molecular analogues is their much-improved biocompatibility, which enables longer term studies on living systems and might constitute a keystone and determining feature of this strategy towards its possible future use in a biomedical context.

\section{ASSOCIATED CONTENT}

Supporting Information. Detailed synthetic procedures, hardcopies of $1 \mathrm{H}$ and 13C NMR spectra for all new molecules and polymers, conditions for separation of chromophoric macroinitiators by preparative HPLC on chiral stationary phases and associated chromatograms, complementary fluorescence studies (chart) regarding the dependence on fluorescence quantum yield to polymer length, hard-copies of all DOSY NMR spectra used in the study.

\section{AUTHORS INFORMATION}

Corresponding Author

magali.gary-bobo@inserm.fr, cyrille.monnereau@ens-lyon.fr

\section{Present Addresses}

$†$ Department of Chemistry and Chemical Engineering, Chalmers University of Technology, Göteborg 412 96, Sweden

\section{Funding Sources}

The imaging facility MRI is a member of the national infrastructure France-BioImaging supported by the French National Research Agency (ANR-10-INBS-04, «Investments for the future»).

\section{ACKNOWLEDGMENTS}

All authors would like to thank Mireille Rossel and Nicolas Cubedo for their technical assistance in zebrafish experiments. In addition, we acknowledge the imaging facility MRI for allowing access to the imaging platform.

\section{ABBREVIATIONS}

ATRP, Atom-Transfer Radical Polymerization; CDCl3, deuterated chloroform; DLS, Dynamic Light Scattering; DMSO-d6, deuterated dimethylsulfoxide; DOSY, Diffusion Ordered Spectroscopy; fD2O, volume fraction of deuterated water; LSM, Laser-Scanning Microscope; NMR, Nuclear Magnetic Resonance; TBAF, tetrabutylammonium fluoride.

\section{REFERENCES}

1. Helmchen, F.; Denk, W., Deep tissue two-photon microscopy. Nat. Methods 2005, 2 (12), 932-940.

$2 . \quad$ So, P. T. C.; Dong, C. Y.; Masters, B. R.; Berland, K. M., Two-Photon Excitation Fluorescence Microscopy. Annu. Rev. Biomed. Eng. 2000, 2 (1), 399-429.

3. Ellis-Davies, G. C. R., Two-Photon Microscopy for Chemical Neuroscience. ACS Chem. Neurosci. 2011, 2 (4), 185197.

4. $\quad$ Shih, A. Y.; Driscoll, J. D.; Drew, P. J.; Nishimura, N.; Schaffer, C. B.; Kleinfeld, D., Two-Photon Microscopy as a Tool to Study Blood Flow and Neurovascular Coupling in the Rodent Brain. J. Cereb. Blood Flow Metab. 2012, 32 (7), 1277-1309.

5. $\quad$ McDole, K.; Xiong, Y.; Iglesias, P. A.; Zheng, Y., Lineage mapping the pre-implantation mouse embryo by two-photon microscopy, new insights into the segregation of cell fates. Dev. Biol. 2011, 355 (2), 239-249.

6. Schenke-Layland, K.; Riemann, I.; Damour, O.; Stock, U. A.; König, K., Two-photon microscopes and in vivo multiphoton tomographs - Powerful diagnostic tools for tissue engineering and drug delivery. Adv. Drug Deliv. Rev. 2006, 58 (7), 878-896.

7. Ibraheem, A.; Campbell, R. E., Designs and applications of fluorescent protein-based biosensors. Curr. Opin. Chem. Biol 2010, 14 (1), 30-36.

8. $\quad$ Miller, D. R.; Jarrett, J. W.; Hassan, A. M.; Dunn, A. K., Deep tissue imaging with multiphoton fluorescence microscopy. Curr. Opin. Biomed. Eng 2017, 4, 32-39.

9. Drobizhev, M.; Makarov, N. S.; Tillo, S. E.; Hughes, T. E.; Rebane, A., Two-photon absorption properties of fluorescent proteins. Nat. Methods 2011, 8 (5), 393-399. 
10. Yao, S.; Belfield, K. D., Two-Photon Fluorescent Probes for Bioimaging. Eur. J. Org. Chem. 2012, 2012 (17), 3199-3217.

11. Lou, X.; Zhao, Z.; Tang, B. Z., Organic Dots Based on AIEgens for Two-Photon Fluorescence Bioimaging. Small 2016, 12 (47), 6430-6450.

12. Adjili, S.; Favier, A.; Fargier, G.; Thomas, A.; Massin, J.; Monier, K.; Favard, C.; Vanbelle, C.; Bruneau, S.; Peyriéras, N.; Andraud, C.; Muriaux, D.; Charreyre, M.-T., Biocompatible photoresistant far-red emitting, fluorescent polymer probes, with near-infrared two-photon absorption, for living cell and zebrafish embryo imaging. Biomaterials 2015, 46, 70-81.

13. Bui, A. T.; Beyler, M.; Grichine, A.; Duperray, A.; Mulatier, J.-C.; Guyot, Y.; Andraud, C.; Tripier, R.; Brasselet, S.; Maury, O., Near infrared two photon imaging using a bright cationic $\mathrm{Yb}(\mathrm{iii})$ bioprobe spontaneously internalized into live cells. Chem. Commun. 2017, 53 (44), 6005-6008.

14. Navarro, J. R. G.; Lerouge, F.; Cepraga, C.; Micouin, G.; Favier, A.; Chateau, D.; Charreyre, M.-T.; Lanoë, P.-H.; Monnereau, C.; Chaput, F.; Marotte, S.; Leverrier, Y.; Marvel, J.; Kamada, K.; Andraud, C.; Baldeck, P. L.; Parola, S., Nanocarriers with ultrahigh chromophore loading for fluorescence bioimaging and photodynamic therapy. Biomaterials 2013, 34 (33), 8344-8351.

15. Monnereau, C.; Marotte, S.; Lanoë, P.-H.; Maury, O.; Baldeck, P. L.; Kreher, D.; Favier, A.; Charreyre, M.-T.; Marvel, J.; Leverrier, Y.; Andraud, C., Water-soluble chromophores with star-shaped oligomeric arms: synthesis, spectroscopic studies and first results in bio-imaging and cell death induction. New J. Chem. 2012, 36 (11), 2328-2333.

16. Massin, J.; Charaf-Eddin, A.; Appaix, F.; Bretonnière, Y.; Jacquemin, D.; van der Sanden, B.; Monnereau, C.; Andraud, C., A water soluble probe with near infrared two-photon absorption and polarity-induced fluorescence for cerebral vascular imaging. Chem. Sci. 2013, 4 (7), 2833-2843.

17. Pascal, S.; Denis-Quanquin, S.; Appaix, F.; Duperray, A.; Grichine, A.; Le Guennic, B.; Jacquemin, D.; Cuny, J.; Chi, S.-H.; Perry, J. W.; van der Sanden, B.; Monnereau, C.; Andraud, C.; Maury, O., Keto-polymethines: a versatile class of dyes with outstanding spectroscopic properties for in cellulo and in vivo two-photon microscopy imaging. Chem. Sci. 2017, 8 (1), 381394.

18. Mettra, B.; Appaix, F.; Olesiak-Banska, J.; Le Bahers, T.; Leung, A.; Matczyszyn, K.; Samoc, M.; van der Sanden, B.; Monnereau, C.; Andraud, C., A Fluorescent Polymer Probe with High Selectivity toward Vascular Endothelial Cells for and beyond Noninvasive Two-Photon Intravital Imaging of Brain Vasculature. ACS Appl. Mater. Interfaces 2016, 8 (27), 1704717059.

19. Deiana, M.; Mettra, B.; Matczyszyn, K.; Piela, K.; Pitrat, D.; Olesiak-Banska, J.; Monnereau, C.; Andraud, C.; Samoc, M., Interactions of a biocompatible water-soluble anthracenyl polymer derivative with double-stranded DNA. Phys. Chem. Chem. Phys. 2015, 17 (45), 30318-30327.

20. Deiana, M.; Mettra, B.; Martinez-Fernandez, L.; Mazur, L. M.; Pawlik, K.; Andraud, C.; Samoc, M.; Improta, R.; Monnereau, C.; Matczyszyn, K., Specific Recognition of GQuadruplexes Over Duplex-DNA by a Macromolecular NIR Two-Photon Fluorescent Probe. J. Phys. Chem. Lett. 2017, 8 (23), 5915-5920.

21. Deiana, M.; Mettra, B.; Matczyszyn, K.; Pitrat, D.; Olesiak-Banska, J.; Monnereau, C.; Andraud, C.; Samoc, M., Unravelling the Binding Mechanism of a Poly(cationic) Anthracenyl Fluorescent Probe with High Affinity toward
Double-Stranded DNA. Biomacromolecules 2016, 17 (11), 3609-3618.

22. Deiana, M.; Mettra, B.; Mazur, L. M.; Andraud, C.; Samoc, M.; Monnereau, C.; Matczyszyn, K., Two-Photon Macromolecular Probe Based on a Quadrupolar Anthracenyl Scaffold for Sensitive Recognition of Serum Proteins under Simulated Physiological Conditions. ACS Omega 2017, 2 (9), 5715-5725.

23. Yang, Z.; Chi, Z.; Mao, Z.; Zhang, Y.; Liu, S.; Zhao, J.; Aldred, M. P.; Chi, Z., Recent advances in mechano-responsive luminescence of tetraphenylethylene derivatives with aggregation-induced emission properties. Mater. Chem. Front. 2018, 2 (5), 861-890.

24. Leung, N. L. C.; Xie, N.; Yuan, W.; Liu, Y.; Wu, Q.; Peng, Q.; Miao, Q.; Lam, J. W. Y.; Tang, B. Z., Restriction of Intramolecular Motions: The General Mechanism behind Aggregation-Induced Emission. Chem. Eur. J. 2014, 20 (47), 15349-15353.

25. Zhao, Z.; Zhang, H.; Lam, J. W. Y.; Tang, B. Z., Aggregation-Induced Emission: New Vistas at the Aggregate Level. Angew. Chem. Int. Ed. 2020, 59 (25), 9888-9907.

26. Lin, J.; Zeng, X.; Xiao, Y.; Tang, L.; Nong, J.; Liu, Y.; Zhou, H.; Ding, B.; Xu, F.; Tong, H.; Deng, Z.; Hong, X., Novel nearinfrared II aggregation-induced emission dots for in vivo bioimaging. Chem. Sci. 2019, 10 (4), 1219-1226.

27. Tong, H.; Hong, Y.; Dong, Y.; Häußler, M.; Lam, J. W. Y.; Li, Z.; Guo, Z.; Guo, Z.; Tang, B. Z., Fluorescent "light-up" bioprobes based on tetraphenylethylene derivatives with aggregation-induced emission characteristics. Chem. Commun. 2006, (35), 3705-3707.

28. Zhu, X.; Wang, J.-X.; Niu, L.-Y.; Yang, Q.-Z., AggregationInduced Emission Materials with Narrowed Emission Band by Light-Harvesting Strategy: Fluorescence and Chemiluminescence Imaging. Chem. Mater. 2019, 31 (9), 35733581.

29. Wang, Z.; Yong, T.-Y.; Wan, J.; Li, Z.-H.; Zhao, H.; Zhao, Y.; Gan, L.; Yang, X.-L.; Xu, H.-B.; Zhang, C., TemperatureSensitive Fluorescent Organic Nanoparticles with AggregationInduced Emission for Long-Term Cellular Tracing. ACS Appl. Mater. Interfaces 2015, 7 (5), 3420-3425.

$30 . \quad$ Li, B.; Chen, T.; Wang, Z.; Guo, Z.; Peña, J.; Zeng, L.; Xing, J., A novel cross-linked nanoparticle with aggregation-induced emission properties for cancer cell imaging. J. Mater. Chem. B 2020, 8 (12), 2431-2437.

31. Zhang, N.; Chen, H.; Fan, Y.; Zhou, L.; Trépout, S.; Guo, J.; Li, M.-H., Fluorescent Polymersomes with AggregationInduced Emission. ACS Nano 2018, 12 (4), 4025-4035.

32. Rouillon, J.; Blahut, J.; Jean, M.; Albalat, M.; Vanthuyne, N.; Lesage, A.; Ali, L. M. A.; Hadj-Kaddour, K.; Onofre, M.; GaryBobo, M.; Micouin, G.; Banyasz, A.; Le Bahers, T.; Andraud, C.; Monnereau, C., Two-Photon Absorbing AIEgens: Influence of Stereoconfiguration on Their Crystallinity and Spectroscopic Properties and Applications in Bioimaging. ACS Appl. Mater. Interfaces 2020, 12 (49), 55157-55168.

33. Reisch, A.; Klymchenko, A. S., Fluorescent Polymer Nanoparticles Based on Dyes: Seeking Brighter Tools for Bioimaging. Small 2016, 12 (15), 1968-1992.

34. Collot, M.; Schild, J.; Fam, K. T.; Bouchaala, R.; Klymchenko, A. S., Stealth and Bright Monomolecular Fluorescent Organic Nanoparticles Based on Folded Amphiphilic Polymer. ACS Nano 2020, 14 (10), 13924-13937. 35. Gamucci, 0.; Bertero, A.; Gagliardi, M.; Bardi, G., Biomedical Nanoparticles: Overview of Their Surface ImmuneCompatibility. Coatings 2014, 4 (1), 139-159. 
36. Viéville, J.; Tanty, M.; Delsuc, M.-A., Polydispersity index of polymers revealed by DOSY NMR. J. Magn. Reson. 2011, 212 (1), 169-173.

37. de Reguardati, S.; Pahapill, J.; Mikhailov, A.; Stepanenko, Y.; Rebane, A., High-accuracy reference standards for two-photon absorption in the 680\&\#x2013;1050 nm wavelength range. Opt. Express 2016, 24 (8), 9053-9066.

38. Harris, M. C.; Huang, X.; Buchwald, S. L., Improved Functional Group Compatibility in the Palladium-Catalyzed Synthesis of Aryl Amines. Org. Lett. 2002, 4 (17), 2885-2888.

39. Ma, C.; Sun, W.; Xu, L.; Qian, Y.; Dai, J.; Zhong, G.; Hou, Y.; Liu, J.; Shen, B., A minireview of viscosity-sensitive fluorescent probes: design and biological applications. J. Mater. Chem. B 2020, 8 (42), 9642-9651.

40. Rouillon, J.; Monnereau, C.; Andraud, C., Reevaluating the Solution Photophysics of Tetraphenylethylene at the Origin of their Aggregation-Induced Emission Properties. Chem. Eur. J. 2021, 27 (30), 8003-8007.

41. Parenti, F.; Tassinari, F.; Libertini, E.; Lanzi, M.; Mucci, A., $\Pi$-Stacking Signature in NMR Solution Spectra of ThiopheneBased Conjugated Polymers. ACS Omega 2017, 2 (9), 57755784 .
42. Appukuttan, V. K.; Dupont, A.; Denis-Quanquin, S.; Andraud, C.; Monnereau, C., Mild and efficient bromination of poly(hydroxyethyl acrylate) and its use towards ionic-liquid containing polymers. Polym. Chem. 2012, 3 (10), 2723-2726.

43. Nieto-Draghi, C.; Ávalos, J. B.; Rousseau, B., Transport properties of dimethyl sulfoxide aqueous solutions. J. Chem. Phys. 2003, 119 (9), 4782-4789.

44. LeBel, R. G.; Goring, D. A. I., Density, Viscosity, Refractive Index, and Hygroscopicity of Mixtures of Water and Dimethyl Sulfoxide. Journal of Chemical \& Engineering Data 1962, 7 (1), 100-101.

45. Hinton, D. P.; Johnson, C. S., Diffusion ordered 2D NMR spectroscopy of phospholipid vesicles: determination of vesicle size distributions. J. Phys. Chem. 1993, 97 (35), 9064-9072.

46. Canzi, G.; Mrse, A. A.; Kubiak, C. P., Diffusion-Ordered NMR Spectroscopy as a Reliable Alternative to TEM for Determining the Size of Gold Nanoparticles in Organic Solutions. J. Phys. Chem. C 2011, 115 (16), 7972-7978. 